\title{
Initial Assessment of Sulfur-lodine Process Safety Issues and How They May Affect Pilot Plant Design and Operation
}

Robert S. Cherry

September 2006

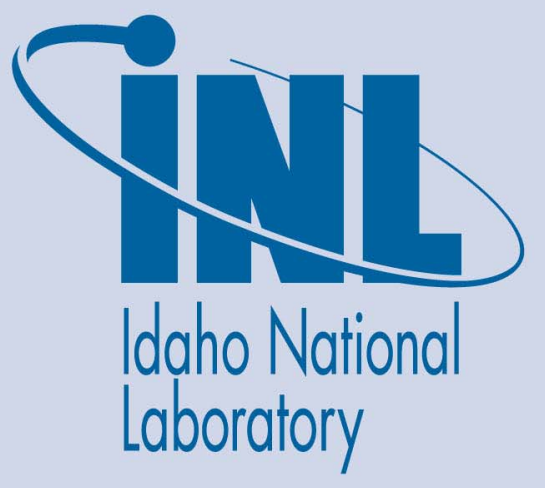

The INL is a U.S. Department of Energy National Laboratory operated by Battelle Energy Alliance 


\section{Initial Assessment of Sulfur-lodine Process Safety Issues and How They May Affect Pilot Plant Design and Operation}

Robert S. Cherry

September 2006

Idaho National Laboratory

Idaho Falls, Idaho 83415

Prepared for the

U.S. Department of Energy

Assistant Secretary for Fossil Energy

Under DOE Idaho Operations Office

Contract DE-AC07-05ID14517 


\section{SUMMARY}

The sulfur-iodine process to make hydrogen by the thermochemical splitting of water is under active development as part of a U.S. Department of Energy program. An integrated lab scale system is currently being designed and built. The next planned stage of development is a pilot plant with a thermal input of about $500 \mathrm{~kW}$, equivalent to about 30,000 standard liters per hour of hydrogen production. The sulfur-iodine process contains a variety of hazards, including temperatures up to $850{ }^{\circ} \mathrm{C}$ and hazardous chemical species including $\mathrm{SO}_{2}, \mathrm{H}_{2} \mathrm{SO}_{4}, \mathrm{HI}$, $\mathrm{I}_{2}$, and of course $\mathrm{H}_{2}$. The siting and design of a pilot plant must consider these and other hazards. This report presents an initial analysis of the hazards that might affect pilot plant design and should be considered in the initial planning.

The general hazards that have been identified include reactivity, flammability, toxicity, pressure, electrical hazards, and industrial hazards such as lifting and rotating equipment. Personnel exposure to these hazards could occur during normal operations, which includes not only running the process at the design conditions but also initial inventory loading, heatup, startup, shutdown, and system flushing before equipment maintenance. Because of the complexity and severity of the process, these ancillary operations are expected to be performed frequently. In addition, personnel could be exposed to the hazards during various abnormal situations which could include unplanned phase changes of liquids or solids, leaks of process fluids or cooling water into other process streams, unintentional introducion of foreign species into the process, and unexpected side reactions.

Design of a pilot plant will also be affected by various codes and regulations such as the International Building Code, the International Fire Code, various National Fire Protection Association Codes, and the Emergency Planning and Community Right-to-Know Act. 


\section{CONTENTS}

SUMMARY

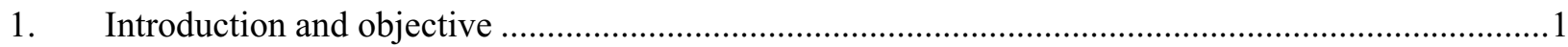

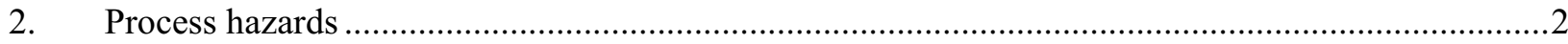

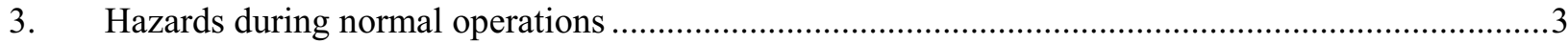

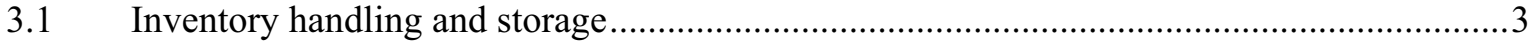

3.2 Thermal expansion during warmup or cooldown .............................................................

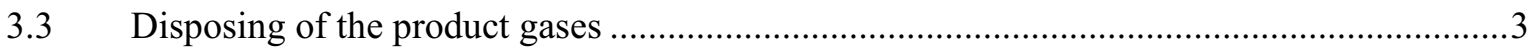

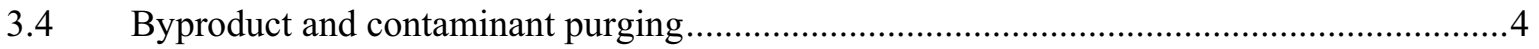

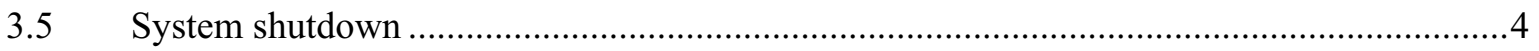

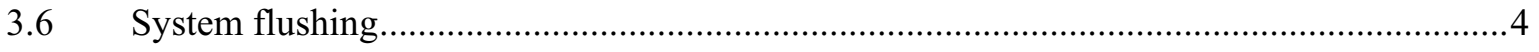

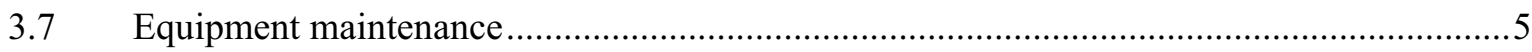

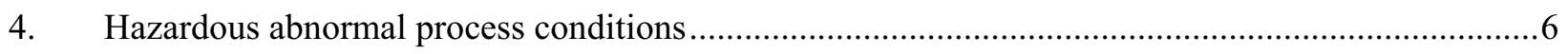

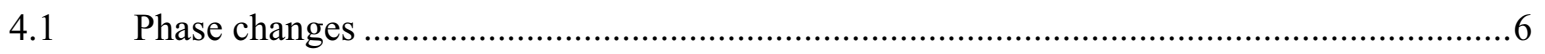

4.2 Unintended mixing of process fluids ...................................................................... 6

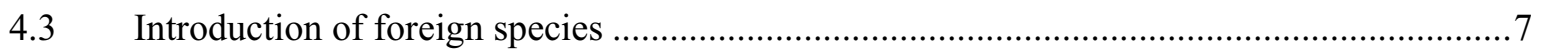

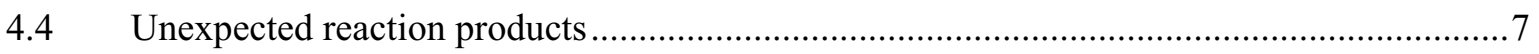

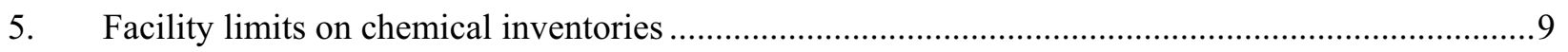

\section{TABLES}

Table 1 Inventory limits on S-I chemicals under the International Building Code..................................10

Table 2 NFPA limits on chemical inventories in sprinklered areas ...................................................... 10 


\section{Initial Assessment of Sulfur-lodine Process Safety Issues and How They May Affect Pilot Plant Design and Operation}

\section{Introduction and objective}

The United States Department of Energy is funding development of a process to make hydrogen from water using heat from a nuclear reactor for energy ${ }^{1}$. The process uses three chemical reactions which, in total, give the desired net reaction. Because of the reagents involved, this process is known as the sulfur-iodine cycle:

$$
\begin{aligned}
2 \mathrm{H}_{2} \mathrm{O}+\mathrm{SO}_{2}+\mathrm{I}_{2} & \rightarrow \mathrm{H}_{2} \mathrm{SO}_{4}+2 \mathrm{HI} \\
\mathrm{H}_{2} \mathrm{SO}_{4} & \rightarrow \mathrm{H}_{2} \mathrm{O}+\mathrm{SO}_{2}+1 / 2 \mathrm{O}_{2} \\
2 \mathrm{HI} & \rightarrow \mathrm{I}_{2}+\mathrm{H}_{2}
\end{aligned}
$$

These reactions operate at about 220,850 , and $400{ }^{\circ} \mathrm{C}$ respectively and at moderate pressures below about $100 \mathrm{psig}$. The second reaction, decomposition of sulfuric acid, is endothermic (hence the use for nuclear heat) while the first and third are exothermic. However, in the expected process configuration the $\mathrm{HI}$ decomposition requires significant heating of the feed stream and is therefore a net energy consumer. In addition to these materials, concentrated $\mathrm{H}_{3} \mathrm{PO}_{4}$ solution is used after the first reaction to separate $\mathrm{HI}$ from unreacted $\mathrm{H}_{2} \mathrm{O}$ and $\mathrm{I}_{2}$. It too is recovered and recycled in the process.

This document provides a preliminary evaluation of major safety and environmental issues that must be addressed as part of the design of a larger scale pilot plant, nominally about $500 \mathrm{~kW}$ thermal input or equivalent to production of about 30,000 standard liters of hydrogen per hour. It is largely based on a design described in a recent project milestone report $^{2}$. Because maintenance and operations activities can be hazardous in ways that are distinct from process hazards, design issues which address them have also been included where they can be foreseen. This early guidance is provided to facilitate planning for the pilot plant, including selection of a building for it. A formal hazard assessment and design review must still be done when the designs are more developed.

\footnotetext{
${ }^{1}$ J. M. Borgard et al.. High Efficiency Hydrogen Production from Nuclear Energy:Laboratory Demonstration of S-I Water-Splitting, International Nuclear Energy Research Initiative project final report 2002-001-F, November 2005

${ }^{2}$ B. Russ et al., Conceptual Design for a $500 \mathrm{KW}$ Sulfur-Iodine Thermochemical Cycle Pilot Scale Experiment, General Atomics, September 2005
} 


\section{Process hazards}

The sulfur-iodine process contains a variety of potential hazards to equipment, personnel, and the environment. While most of these have been identified in the smaller integrated lab scale system now being designed and assembled ${ }^{3,4}$, the larger scale of a pilot plant adds other hazards. The complete list includes the following:

- Reactivity - The product oxygen can accelerate or spontaneously initiate combustion of flammable materials. Sulfur trioxide and concentrated sulfuric acid are strong oxidizing agents which can react with other materials. Reactions that corrode the system piping will cause leaks of acids or toxic gases.

- Flammability - The product hydrogen is quite flammable and can be detonable under certain conditions. Oxygen to burn it exists both in the process and in the outside atmosphere.

- Toxicity - Most of the species in the process $\left(\mathrm{H}_{2} \mathrm{SO}_{4}, \mathrm{SO}_{2}, \mathrm{SO}_{3}, \mathrm{HI}, \mathrm{I}_{2}, \mathrm{H}_{3} \mathrm{PO}_{4}\right)$ are toxic, primarily with immediate destructive effects on tissue.

- Thermal hazards - All parts of the process operate at temperatures sufficient to cause personal injury or fires if contact is not controlled. High temperature steam is a particularly severe burn hazard.

- Pressure/kinetic energy - The system pressure and volume are not unusually large, so the kinetic energy hazard of accidental leaks or minor equipment breakage is not a major concern. Pressure relief will be needed in closed systems because of volume changes during solid-liquid and liquid-gas phase changes or thermal expansion of liquids over the expected temperature ranges.

- Electrical hazards - The pilot scale process uses 500 kilowatts of thermal input supplied by electric heaters, which means that a substantial supply of electricity at high voltage will be available to the unit.

- Industrial hazards - The scale of equipment will create lifting hazards during both installation and maintenance. Rotating equipment such as pumps will present hazards to fingers. Secondary containment used for pressure protection or toxic gas leak control creates issues for confined space entry.

This preliminary review assumes that as the first step of controlling these hazards a selfconsistent set of design conditions will be used for the several process subsystems and that these subsystems will be built in accord with relevant mechanical or electrical design codes and standards. In addition, it anticipates the use of standard controls for the industrial hazards such as leak checks before operation, thermal insulation on exposed hot surfaces, and guards on rotating equipment.

\footnotetext{
${ }^{3}$ E. Parma, Preliminary Safety Analysis Report for the Sulfuric Acid Section of the Integrated lab Scale Experiment, Sandia National Laboratories, June 2006.

${ }^{4}$ B. Wong, Safety Analysis for the Sulfur Iodine Integrated Laboratory-Scale Experiment, General Atomics report GA-C25485, June 2006.
} 


\section{Hazards during normal operations}

The inventory of process hazards does not illustrate how an operator might come in contact with them. This section discusses some routine operations activities that could lead to personnel exposure or equipment damage but which can be addressed in the system design. Other exposure mechanisms will likely become evident as the layout, design, and planned activities are specified in more detail.

\subsection{Inventory handling and storage}

The flows of liquids through this process will be on the order of $200 \mathrm{~L} / \mathrm{hr}$, based on scaleup of the integrated lab scale system now under design with a hydrogen production rate of 200 standard liters per hour, or 1/150th the size proposed for the pilot plant. With intermediate storage tanks of eight hours capacity normally running half full, the inventory of process materials will be on the order of 800 liters (211 gallons) with weights of at least $1400 \mathrm{~kg}(3170 \mathrm{lb})$. This does not include materials held in storage for future use. This quantity of concentrated acids or solid iodine will require careful planning of the storage space to allow proper spill control and the loading equipment to assure operator safety during material handling.

\subsection{Thermal expansion during warmup or cooldown}

Because parts of the process run at temperatures near 400 and $900{ }^{\circ} \mathrm{C}$, thermal expansion during warmup must be carefully considered to prevent overstressing the piping or the vessels in the system. Depending on the operating procedures used, the thermal stresses during shutdown and cooldown may be different from those of warmup. The thermal stress consequences of sudden cooling from activating fire sprinklers over the unit while it is operating (perhaps because of a fire in unrelated equipment) must be considered.

Because the relatively small scale of this system suggests that small diameter tubing will be sufficient to carry the flows, the normal flexibility of tubing systems will likely accommodate its full thermal expansion. This must be confirmed when the layout is finalized. Although a standard solution to large thermal expansions in piping is to install thin-walled expansion bellows, it may not be possible to fabricate these because any material of construction will likely carry a significant corrosion allowance. In the vessels of this system, the use of several materials of construction (especially corrosion-resistant glass liners inside a metal pressure-containing envelope) can present problems with differential thermal expansion within a single piece of equipment.

\subsection{Disposing of the product gases}

The oxygen and hydrogen produced by this process will require special handling. Oxygen likely can be vented directly into the atmosphere as long as the plume can be kept away from the air intakes of other combustion equipment including motor vehicles. The hydrogen will be more difficult because of the amount that must be handled: about 30,000 liters/hour at standard conditions, equivalent to about $100 \mathrm{~kW}$ of heat if oxidized to water. Diluting this stream to less than $25 \%$ of the lower flammable limit will require about 1800 cubic feet per minute of air, an amount achievable with a ventilation blower. 
Complicating either oxidation or dilution, however, the provisional hydrogen product contains $6 \mathrm{~mol} \% \mathrm{HI}$ vapor, or about $11.5 \mathrm{~kg} /$ hour. Routine discharge of this amount of $\mathrm{HI}$ is unlikely to be acceptable for environmental, process, or economic reasons.

\subsection{Byproduct and contaminant purging}

Though the feeds and products of the overall process are simple enough — water in, hydrogen and oxygen gases out - the implementation will require additional purge and waste streams. Liquid or solid contaminants such as feedstock impurities, corrosion products, or reaction byproducts have no purge route in the basic flow sheet unless one is added. Because there are three main recycle loops in the process (one each for $\mathrm{SO}_{2}, \mathrm{I}_{2}$, and $\mathrm{H}_{3} \mathrm{PO}_{4}$ ), several purge points may be needed. These purges might be continuous or intermittent manual operations. Process purges would also be needed if a major upset alters the composition of streams or material stored between process sections in a way that prevents their reuse. Those materials will then have to be discarded.

Because these purges and waste streams will contain hazardous process species, they will require either neutralization before they are disposed or special handling afterward. These operations create opportunities for inadvertent personnel exposure because they will not be routine.

\subsection{System shutdown}

In a normal shutdown the electrical power demand could be ramped down gradually. In a emergency shutdown triggered by operators or by the control system, it is likely that all the process heaters would be immediately depowered. Because they will total 600-800 $\mathrm{kW}$ of design capacity to assure that they can deliver the specified $500 \mathrm{~kW}$, the electrical system supplying this power could see a sudden large drop in load. The consequences of this for electrical system stability and on other equipment remaining on-line must be assessed. Fortunately, these heaters are resistive loads rather than inductive or capacitive loads which would create greater problems in a shutdown.

\subsection{System flushing}

Before the system can be opened for any type of maintenance, it will have to be flushed to remove the hazardous species and to cool the equipment. This will create a large volume of contaminated gas (air, nitrogen, or possibly steam) or liquid water, all of them containing acidic species. Because $\mathrm{I}_{2}$ is not soluble in water, the system might be designed to blow the liquid out of iodine-bearing lines with hot gas which would then contain significant volatile iodine. Any flush fluid will need to be treated before it can discharged since both the air and water must meet environmental discharge criteria.

The piping should be designed to self-drain to the extent possible to intermediate storage vessels. Low point drains should be installed where liquid might be trapped during shutdowns, steam purging, or water flushing. These drains will be used to clear the lines before they are opened for maintenance or before the unit is restarted. They should be easily accessible even if the unit is hot. To avoid operator exposure to hazardous chemicals, these drains should be piped to a chemical sewer or to removable carboys. 
In the event of a spill of process fluids from either piping drains or a vessel leak, the spill will have to be contained, collected, and treated. If the building where the system is located does not have an acid drain system already, a catch basin under each equipment item or built into the floor of each skid will be necessary. In cleaning up such a spill a large amount of rinse water requiring treatment would be generated. The floor drains under safety showers might also require collection for treatment before discharge.

\subsection{Equipment maintenance}

Because of the process' complexity and severity, this pilot plant will likely require a large amount of mechanical and instrument maintenance. This work introduces the chance for accidents or injuries. Recognizing this before the detailed design is started allows the incorporation of several features to greatly simplify that work.

- Locate equipment with foreseeable maintenance needs near the outside of the skids for access and avoid piping or structural interferences around these items.

- Install permanent work platforms near elevated equipment that might need regular attention rather than relying on portable ladders for access.

- Provide lifting lugs on heavy items that might be removed for maintenance, for instance pumps whose shafts or seals might corrode.

- Assure overhead access for a bridge crane or portable crane to handle large and heavy equipment, and provide hoisting tie points or a beam-mounted trolley over moderate size equipment to allow the use of manual pulleys or winches. Provide a clear path to a lay-down area.

- To simplify confined space entry issues, to the extent possible avoid installing maintained equipment in person-sized enclosures such as plastic-enclosed ventilated compartments or separate external pressure shells.

- Provide flanged connections at equipment or piping that must be removed for maintenance.

- The electrical power supply and the process chemicals both present hazards that must be locked-out before maintenance can be done on the unit. If it is not possible to lock-out the power to the process pumps, assure that lockable isolation valves are provided where needed.

A potential larger-scale maintenance problem is that the many corrosive liquids and gases in the process could cause degradation of external systems if they leak even slowly. In particular, acid attack on vessel support structures or welds could lead to their failure and the collapse of part of the system. Similarly, attack on electrical insulation or barriers by corrosive vapors could lead to the unintentional electrification of parts of the system. Corrosion of process instruments could lead to failure to detect a hazardous situation. A program of regular visual inspection and instrumental monitoring to detect corrosioncaused problems outside the process piping will be valuable in preventing this problem. 


\section{Hazardous abnormal process conditions}

This section addresses situations which would significantly change the process conditions or operation from those expected in the design. While each is physically plausible, the current process detail is not sufficient to spell out how they might occur in this system. They might not be problems in practice. Assessing their hazard potential will require additional process information, expert review, or specific laboratory investigation.

\subsection{Phase changes}

Elemental iodine, a major component of several streams, has a relatively high melting point of $114^{\circ} \mathrm{C}$. Sulfur trioxide's melting point is similar at $63{ }^{\circ} \mathrm{C}$, and $100 \% \mathrm{H}_{3} \mathrm{PO}_{4}$ melts at $42{ }^{\circ} \mathrm{C}$. At process conditions they will be liquids. During shutdowns, however, process equipment could cool to near ambient temperature and plug with the solid form of these materials, although blending with other process compounds will help by reducing the mixture melting points. Shutdown procedures that drain lines and vessels can limit the problem. However, preheating of these vessels and lines will be necessary to prevent freezing when these liquids are first reintroduced. While these materials can be allowed to freeze, this complicates restart because of the time to melt them. Plans to solidify and remelt iodine in piping or storage vessels must consider the consequences of its $25 \%$ volume increase upon melting.

These high melting points will be especially significant in the design of pressure relief lines which must carry these streams for a long distance to a discharge point. A large mass of ambient temperature pipe downstream of the relief device could cause the fluid to freeze and restrict the relief line. This might not be noticed until the next time the relief device opens. Solids could also plug the inlet side of a relief device during normal operation if that stagnant section of piping is not purged or heat traced.

A second phase change problem is associated with process streams that are liquids either at their boiling point or saturated with a gas. Sudden depressuring of such a stream can generate a large amount of a flashing two phase mixture, similar to opening a shaken can of soda. This situation risks carrying liquid where it is not expected or hindering the ability of a line or relief system to vent what was expected to be a single-phase fluid.

A related problem might occur in the sulfuric acid decomposition step where the initial process operation is to vaporize concentrated acid. This step is potentially subject to superheating the acid followed by sudden flashing of the mixture and carryover of liquid acid to the downstream equipment. Such flashing could occur when the vaporizer is restarted if it was not purged of deaerated process fluids during the previous shutdown.

\subsection{Unintended mixing of process fluids}

A leak of cooling water into a heat exchanger or misdirection of a water-containing stream into hot process equipment can create a sudden pressure surge when the water boils. Even if the destination equipment is not above the boiling point, adding water to a concentrated sulfuric or phosphoric acid stream creates a large exotherm from the heat of 
solution. This can rapidly lead to local boiling and spattering. A leak like this into equipment that is valved shut might overpressure a vessel.

Alternatively, a leak of almost any of the process fluids outwards into cooling water or other utilities lines creates a risk of personnel exposure to acidic fluids or hazardous gases where they are not expected, such as at a floor drain or a cooling tower.

\subsection{Introduction of foreign species}

There are several avenues for the introduction into this process of trace foreign species which could create problems. One group of trace species is those initially resident in the system when it is started or restarted. Air would introduce several compounds: nitrogen and argon, which should be inert and easily purged; oxygen, which will be purged too but which will require some safety considerations in the hydrogen loop; and carbon dioxide which, though present in air at less than $400 \mathrm{ppm}$ and not being very soluble in either acidic or hot liquids, might in the presence of water and metal ions form insoluble bicarbonate or carbonate salts. Liquid water present from prior flushing with either cold water or steam could unexpectedly boil, raising the system pressure or pushing other liquids through piping. Another initial contaminant might be combustible materials such as pump or valve lubricants or improperly specified polymeric seals. Under the oxidizing conditions of this system, these organic materials could generate a small internal fire or cause coke formation.

The second broad class of trace species are those introduced with the primary reactants. The water feed will undoubtedly be purified with reverse osmosis or other methods, but such systems can fail and the consequences must be planned for. Trace contaminants from this source might include ions such as sodium, calcium, magnesium, chloride, bicarbonate, or sulfate and dissolved gases such as air or chlorine dioxide from potable water disinfection. Other sources of trace species would be contaminants in the initial charges of $\mathrm{H}_{2} \mathrm{SO}_{4}, \mathrm{SO}_{2}, \mathrm{I}_{2}$, and $\mathrm{H}_{3} \mathrm{PO}_{4}$. These contaminants will depend on the source and purity of the reagents, but one that would be problematic is the possibility of trace chlorine in the iodine. Both of these elements are halogens with similar chemical behavior, so they might not be completely separated in an iodine purification process. Chloride ions can cause pitting or stress corrosion cracking in some materials at concentrations in the ppm range, especially at high temperatures and in systems where aqueous solutions are evaporated or boiled because dissolved chloride ions become increasingly concentrated in droplets that are evaporating.

\subsection{Unexpected reaction products}

The S-I process' severe conditions create the potential for unexpected reactions that are not part of the intended chemistry. These reactions might only occur during startup, shutdowns, or upsets when the process conditions are not at the normal flowsheet values. The resulting products, rather than the small amount of reaction that formed them, might lead to other problems.

Corrosion of vessels and piping is the most evident set of secondary reactions. Even if there are purge points in the recycle loops for soluble corrosion products, metal ions will 
still accumulate to some level and be carried around the loops. At the conditions elsewhere in the system they might either catalyze unwanted reactions or form solid precipitates that could plug lines, erode pumps and control valves, or foul heat exchange surfaces. Metal sulfates are one likely such precipitate. Under the oxidizing conditions of this process, such precipitates might also potentially contain metal peroxides or superoxides which would be reactive or explosive when dry.

The sulfur and iodine which give this process its name each can have a variety of oxidation states. The formation of alternative sulfur or iodine species should be considered for the same reasons as corrosion products: accumulation in recycle loops, formation of solids, and potential reactivity issues. The possibility of forming elemental sulfur or $\mathrm{H}_{2} \mathrm{~S}$ under some conditions has been recognized. Beyond this, the sulfur iodide cation $\mathrm{S}_{2} \mathrm{I}_{4}{ }^{2+}$ is known to exist. The formation and further reaction of oxygenated species such as peroxysulfuric acid $\left(\mathrm{HO}-\mathrm{SO}_{2}-\mathrm{OOH}\right)$ or $\mathrm{HIO}, \mathrm{HIO}_{3}, \mathrm{HIO}_{4}$, or $\mathrm{I}_{2} \mathrm{O}_{5}$ (iodic acid anhydride) are other possibilities. These oxygen-iodine species may be highly reactive, based on the properties of the analogous chlorine species. Whether any of these could be formed at conditions in the S-I process, possibly during upsets or transients, is unknown. 


\section{Facility limits on chemical inventories}

The hazards discussed earlier in this report would primarily affect people operating or visiting the unit. To protect the building itself or people (including emergency responders) who might might visit other parts of the facility, various national and international design codes establish design requirements for buildings containing hazards such as oxidizers or flammable gases. Typical requirements include fire-resistant walls, automatic sprinklers, or separation of incompatible activities. These codes also specify the amount of hazardous material that can be stored in a room or building at various levels of design protection. These limits are significant at the scale of an S-I pilot plant, and can possibly prevent installation of the pilot plant in an existing facility or might mandate significant changes to the interior of a new or modified facility.

The International Building Code (IBC) defines a number of occupancy categories for rooms and buildings based on the activities in them and specifies features that must be present to allow each class of occupancy. The in-town research laboratories of the Idaho National Laboratory are generally group B (Business) occupancy, although particular areas such as flammable solvents storage in the chemical storage facility carry higher ratings. The limits for the major chemicals of the S-I process allowable under a non-highhazard classification are listed in Table 1 . Though inventory requirements for a pilot plant can not be determined until the system is designed, the allowable storage inventories of sulfuric acid, sulfur dioxide, and iodine are all about a drum or less, comparable to what might be expected in a pilot plant. The 1000 pounds allowable for iodine seems large, but because it is a dense material with a specific gravity of about 5 the corresponding volume is relatively low. If these limits are exceeded, the building enters high-hazard group H-3 for its inventory of "materials that readily support combustion or that pose a physical hazard". It would be most practical to design the pilot plant area from the start for this occupancy to provide the most flexibility in future operations.

The International Fire Code (IFC), updated in 2006, uses the same allowable inventories as the IBC values in Table 1. However, the IFC specifies building features that are oriented toward personnel safety rather than building protection. Separate chapters of that code address hazardous materials (those with physical hazards such as flammability and reactivity) and materials that toxic or highly toxic. The consequence for an S-I pilot plant is to reinforce the conclusion from the IBC that construction to a higher-than-basic occupancy class appears to be desirable if not strictly necessary.

The National Fire Protection Association (NFPA) also promulgates related codes, with two pertaining to the chemicals of the S-I process: one for compressed gases [NFPA 55] and another for liquid and solid oxidizers [NFPA 430]. The latter code applies to the iodine and has limits for it of 100 tons in segregated storage. This is far beyond the expected inventories and presents no constraint. The compressed gas code, however, is much more restrictive because the compounds it covers, being gases, are far more mobile. The key limits are itemized in Table 2. 
Table 1 Inventory limits on S-I chemicals under the International Building Code

\begin{tabular}{|l|l|r|r|c|}
\hline \multicolumn{1}{|c|}{ Compound } & \multicolumn{1}{|c|}{ Hazard Category } & \multicolumn{2}{c|}{$\begin{array}{c}\text { Maximum Allowable } \\
\text { Quantity, 2 }\end{array}$} & $\begin{array}{c}\text { Hazard } \\
\text { Occupancy }\end{array}$ \\
\hline & & In storage & \multicolumn{1}{|c|}{$\begin{array}{c}\text { Used in closed } \\
\text { system }\end{array}$} & $\begin{array}{c}\text { (if allowable } \\
\text { is exceeded) }\end{array}$ \\
\hline Hydrogen & Flammable gas & $4,000 \mathrm{SCF}$ & $4,000 \mathrm{SCF}$ & $\mathrm{H}-2$ \\
\hline Oxygen & Oxidizing gas & $6,000 \mathrm{SCF}$ & $6,000 \mathrm{SCF}$ & $\mathrm{H}-3$ \\
\hline Sulfuric acid & Water reactive 2 & $200 \mathrm{lb}$ & $100 \mathrm{lb}$ & $\mathrm{H}-3$ \\
& Toxic & $2,000 \mathrm{lb}$ & $1,000 \mathrm{lb}$ & \\
& Corrosive & $2,000 \mathrm{gal}$ & $1,000 \mathrm{gal}$ & \\
\hline Sulfur dioxide & Corrosive & $2,000 \mathrm{gal}$ & $1,000 \mathrm{gal}$ & \\
\hline Sulfur trioxide & Oxidizing gas (liquefied) & $60 \mathrm{gal}$ & $6,000 \mathrm{SCF}$ & $\mathrm{H}-3$ \\
& Toxic & $2,000 \mathrm{lb}$ & $1,000 \mathrm{lb}$ & \\
& (Highly Toxic) & $(40 \mathrm{lb})$ & $(20 \mathrm{lb})$ & \\
& Corrosive & $2,000 \mathrm{gal}$ & $1,620 \mathrm{SCF}$ & \\
\hline lodine & Oxidizer 2 & $1,000 \mathrm{lb}$ & $500 \mathrm{lb}$ & $\mathrm{H}-3$ \\
& Corrosive & $20,000 \mathrm{lb}$ & $2,000 \mathrm{gal}$ & \\
\hline Hydrogen iodide & Corrosive & $2,000 \mathrm{gal}$ & $1,000 \mathrm{gal}$ & \\
\hline Phosphoric acid & Corrosive & $2,000 \mathrm{gal}$ & $1,000 \mathrm{gal}$ & \\
\hline
\end{tabular}

${ }^{1}$ Total of all materials in this class. These limits assume use of approved storage cabinets and automatic sprinklers throughout the building. Materials are stored at ambient temperature but in pressurized cylinders or used at process conditions so the limits for the corresponding gas, liquid, or solid state are reported

${ }^{2}$ A compound with more than one maximum allowable quantity must adhere to the limits for all of them.

${ }^{3}$ One source indicated a hazard category of highly toxic rather than toxic for $\mathrm{SO}_{3}$

Table 2 NFPA limits on chemical inventories in sprinklered areas

\begin{tabular}{|l|c|c|}
\hline Material & $\begin{array}{c}\text { No enclosure } \\
\text { (pilot plant area) }\end{array}$ & Enclosure (storage) \\
\hline Flammable gas $\left(\mathrm{H}_{2}\right)$ & $2000 \mathrm{SCF}$ & $4000 \mathrm{SCF}$ \\
\hline Oxidizing gas $\left(\mathrm{O}_{2}\right)$ & $3000 \mathrm{SCF}$ & $6000 \mathrm{SCF}$ \\
\hline Liquefiable oxidizing gas $\left(\mathrm{SO}_{3}\right)$ & $3000 \mathrm{SCF}$ as gas & 60 gal as liquid \\
\hline Liquefiable corrosive gas $\left(\mathrm{SO}_{3}, \mathrm{HI}\right)$ & $1620 \mathrm{SCF}$ as gas & $600 \mathrm{lb}$ as liquid \\
\hline Liquefiable toxic gas $\left(\mathrm{SO}_{3}\right)$ & $1620 \mathrm{SCF}$ as gas & $600 \mathrm{lb}$ as liquid \\
\hline
\end{tabular}

Not surprisingly, the amounts acceptable by the NFPA code are similar to these accepted by the IBC and IFC. The hydrogen and oxygen limits are not problematic because those gases will be created in the process and then will promptly be separately vented to the atmosphere. The oxygen inventory will count against the allowable inventory of gaseous $\mathrm{SO}_{3}$ because both are oxidizing gases but this should not be a major limitation. Similarly, the limit for corrosive gases applies to the total of the two gases sulfur trioxide and hydrogen iodide (hydroiodic acid). Their limit as gases corresponds to the volume of about seven normal laboratory gas cylinders. 
The Environmental Protection Agency also has regulatory requirements which depend on the amount of chemicals in a facility. Under the Emergency Planning and Community Right-to-Know Act the EPA has identified chemicals for which inventories above a specified Threshold Planning Quantity must be reported to the EPA as well as state and local emergency response personnel. The three S-I process chemicals on that list and their respective Threshold Planning Quantities are: sulfuric acid, $1000 \mathrm{lb}$; sulfur dioxide, 500 $\mathrm{lb}$; and sulfur trioxide, $100 \mathrm{lb}$. These amounts are comparable to the levels that might be expected in a pilot facility. Although the Right-to-Know Act creates notification and planning requirements, it does not impose specific design requirements on an S-I process pilot plant or the building housing it.

The conclusion from this overview is that when inventories of the chemicals in the S-I process reach amounts of a few hundred pounds, specific consequences for building design and environmental planning can result. Planning for pilot plant design must recognize the cost and schedule effects of this. 